\title{
Circulating Levels of Bone and Inflammatory Markers in Gestational Diabetes Mellitus
}

\author{
Deirdre Cocks Eschler, ${ }^{1, * \dagger}$ Georgia Kulina, ${ }^{2, *}$ Adolfo Garcia-Ocana, ${ }^{3}$ Jiawen Li, ${ }^{4}$ Thomas Kraus, ${ }^{5}$ and Carol J. Levy ${ }^{3}$
}

\begin{abstract}
Gestational diabetes mellitus (GDM) can cause short- and long-term complications to the mother and fetus. While the precise mechanisms in preserving glucose balance in a healthy pregnancy are unknown, various growth factors and hormones have been implicated or associated with GDM risk in humans or rodents, including prolactin, tumor necrosis factor alpha (TNF $\alpha$ ), osteoprotegerin (OPG), hepatocyte growth factor (HGF), and receptor activator of nuclear factor-kappa B ligand (RANKL). We aimed to evaluate the relationship of these and other protein markers in women with GDM. In this cross-sectional study, blood samples were collected from pregnant women with GDM and with normal glucose tolerance (NGT) at the 24- to 32-week obstetrical visit, during the 1-h oral glucose challenge test or 3-h oral glucose tolerance test. Blood plasma was analyzed for RANKL, OPG, prolactin, tumor necrosis factor-related apoptosis-inducing ligand (TRAIL), HGF, plasminogen activator inhibitor type 1 (PAI-1), and TNF $\alpha$. Forty-six women with NGT and 47 women with GDM were included (mean \pm standard deviation maternal age 31.6 \pm 5.7 , mean \pm standard deviation gestational age $28.1 \pm 2.2$ weeks). Groups were similar in terms of age, body mass index, gestational age, and race/ethnicity. Serum levels of OPG, prolactin, TRAIL, HGF, PAI-1, and TNF $\alpha$ were similar in both groups. RANKL was lower in GDM subjects $(p=0.019)$. Contrary to previous reports in the literature, we found a lower serum RANKL level in women with GDM. Further investigation is needed to determine whether there are suitable serum markers for diagnosing GDM or determining prognosis or severity.
\end{abstract}

Keywords: gestational diabetes mellitus; hepatocyte growth factor; osteoprotegerin; RANK ligand

\section{Introduction}

Gestational diabetes mellitus (GDM) is a complication of pregnancy with short-term and long-term maternal and fetal consequences. The incidence of GDM is increasing worldwide, with some reports affecting as high as $10 \%$ of pregnancies. ${ }^{1,2}$

GDM is thought to develop as a result of the inability of pancreatic $\beta$ cells to overcome the natural insulin resistance created by placental hormones in the second half of pregnancy as well as a loss of first phase insulin secretion. ${ }^{3}$ Healthy pregnant women adapt to this de- mand by increasing insulin secretion through $\beta$ cell hyperplasia and hypertrophy and, as shown in animal models, when this fails to occur, GDM ensues. ${ }^{4-7}$

Pituitary and placental lactogens are known to play a role in the ability of healthy pregnant women to overcome the increased insulin demands, but the exact molecular mechanisms by which this occurs have yet to be fully elucidated. ${ }^{8,9}$ Alterations in inflammatory markers, bone metabolism, and growth factor signaling have been implicated in abnormal glucose tolerance and other diseases in pregnant women. ${ }^{10-12}$ For example,

${ }^{1}$ Division of Endocrinology and Metabolism, Stony Brook University Hospital, Stony Brook, New York.

${ }^{2}$ Harbor View Medical Services, Division of Endocrinology, Mather Hospital Northwell Health, Port Jefferson, New York.

${ }^{3}$ Division of Endocrinology Diabetes and Bone Disease, Icahn School of Medicine at Mount Sinai, New York, New York.

Departments of ${ }^{4}$ Population Health Science \& Policy and ${ }^{5}$ Center for Therapeutic Antibody Development, Icahn School of Medicine at Mount Sinai, New York, New York. *The first two authors contributed equally.

${ }^{\dagger}$ Address correspondence to: Deirdre Cocks Eschler, MD, Division of Endocrinology and Metabolism, Stony Brook University Hospital, 101 Nicholls Road, HSC 16, Stony Brook, NY 11794, E-mail: deirdre.cocks.eschler@gmail.com

(c) Deirdre Cocks Eschler et al. 2018; Published by Mary Ann Liebert, Inc. This Open Access article is distributed under the terms of the Creative Commons License (http://creativecommons.org/licenses/by/4.0), which permits unrestricted use, distribution, and reproduction in any medium, provided the original work is properly cited. 
osteoprotegerin (OPG) and receptor activator of nuclear factor-kappa B ligand (RANKL), cytokines thought to be predominantly involved in bone metabolism, have shown altered ratios in patients with GDM. ${ }^{12}$ Also, tumor necrosis factor-related apoptosis-inducing ligand (TRAIL), an important factor in apoptosis, has been found to circulate at lower levels in women with hypertensive diseases, whereas elevated plasma levels of plasminogen activator inhibitor type 1 (PAI-1) have been associated with insulin resistance and diabetes. ${ }^{13}$

Hepatocyte growth factor (HGF), a growth factor produced by liver and placental tissues that promotes cell survival and tissue regeneration, has been implicated in mouse models of gestational diabetes. ${ }^{11,14}$ Pregnant mice lacking the HGF receptor, known as c-Met, demonstrate higher blood glucose values and lower plasma insulin levels. ${ }^{11}$ Additionally, circulating levels of tumor necrosis factor alpha (TNF $\alpha)$, have been found to be higher in women with GDM. ${ }^{15-17}$

The purpose of this study was to further evaluate the relationship of various protein markers, including prolactin, HGF, TNF $\alpha$, TRAIL, PAI-1, RANKL, and OPG, with gestational diabetes in women.

\section{Materials and Methods}

This was a two-site, cross-sectional study. A total 102 women who were between 24 and 32 weeks pregnant were consented and recruited for the study at the obstetric clinics at the Icahn School of Medicine at Mount Sinai and Elmhurst Hospital Center in New York between October 3, 2013 and April 21, 2015. IRB (Institutional Review Board) approval was obtained and voluntary patient participation with informed consent occurred for all study subjects. Inclusion criteria were all adult pregnant patients $>18$ years of age who were between 24 and 32 weeks gestation. Exclusion criteria were pre-existing type 1 or type 2 diabetes mellitus. Patients were randomly invited to participate in the study during their routine obstetrics visits by our team. Ten milliliters of blood was collected from each patient during the screening of 1-h oral glucose challenge test (OGCT) or the 3-h oral glucose tolerance test (OGTT) between 24 and 32 weeks gestational age. Charts were subsequently reviewed and women who were sampled during the 1 -h OGTT and had a $1 \mathrm{~h}$ glucose $\geq 135 \mathrm{mg} / \mathrm{dL}$, received a 3-h OGTT. If the patients had a glucose value over 135 and failed to follow up with the 3-h OGTT, their samples were excluded from the analysis. GDM status was diagnosed based on the Carpenter and Costan criteria such that those who had two or more of the following were classified as having GDM; fasting glucose $\geq 95 \mathrm{mg} /$ dL, 1-h glucose $\geq 180 \mathrm{mg} / \mathrm{dL}$, 2 - $\mathrm{h}$ glucose $\geq 155 \mathrm{mg} / \mathrm{dL}$, and 3-h glucose $\geq 140 \mathrm{mg} / \mathrm{dL}$. Patients were divided accordingly to GDM status. Forty-seven patients were diagnosed with GDM, and 46 patients were used as controls. Nine patients were excluded because they did not meet eligibility criteria (Fig. 1).

\section{Blood sampling}

Venous blood samples $(10 \mathrm{~mL})$ were drawn in lavender top tubes with EDTA preservative during the 1-h OGCT or 3-h OGTT. Samples were obtained from women between 24 and 32 weeks of gestation. The samples were placed on ice immediately and centrifuged within $1 \mathrm{~h}$ of collection at $3000 \mathrm{~g}, 4^{\circ} \mathrm{C}$ for $15 \mathrm{~min}$. Plasma was subsequently aliquoted separately and immediately stored at $-80^{\circ} \mathrm{C}$ until assayed.

Multiplex cytokine/chemokine/hormone assay of plasma HGF, RANKL, OPG, TRAIL, prolactin, TNF $\alpha$, and PAI-1 (total) levels

Cytokines/chemokines/hormones levels in human plasma were assessed by Magnetic Bead-Based Multiplex Assays

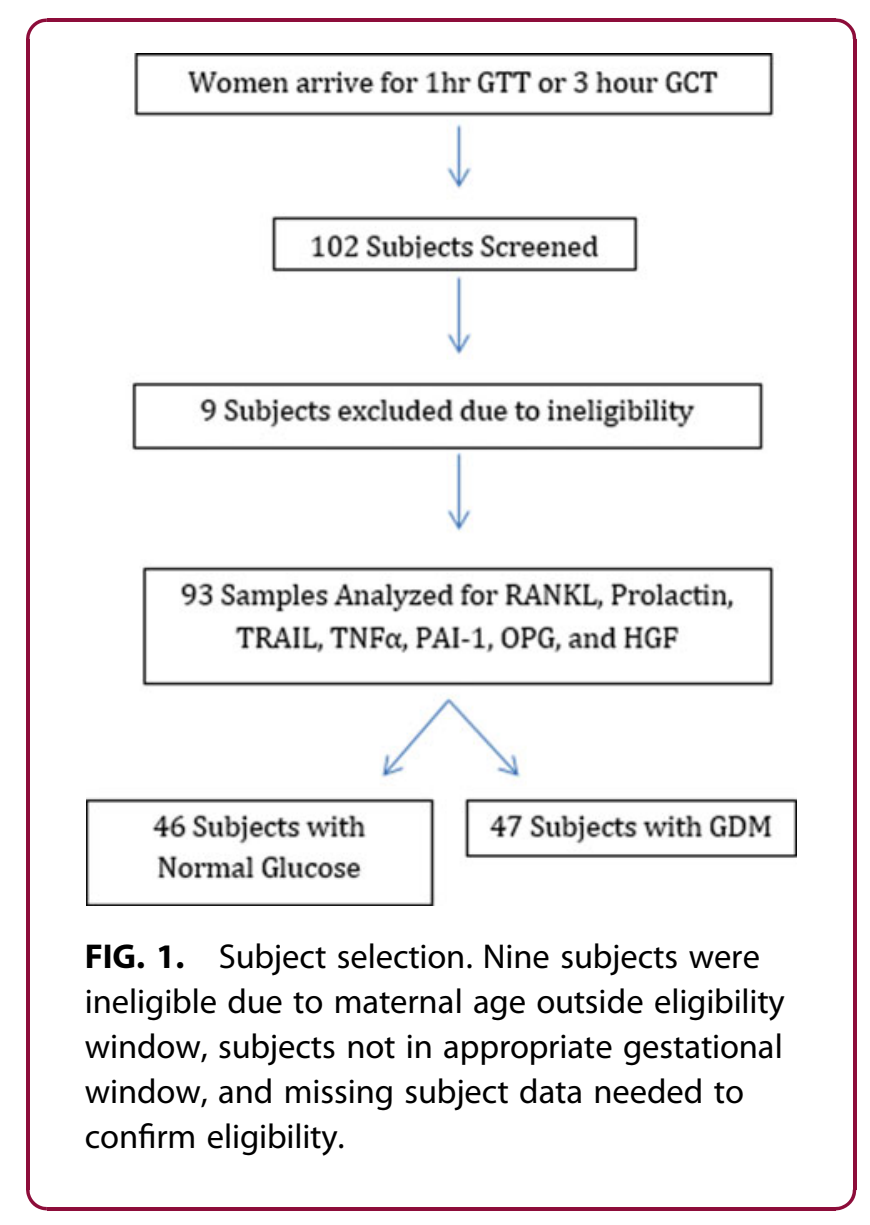


using the Luminex technology (EMD Millipore) following the manufacturer's instruction. Multiplex plates were read using a Luminex 100 multiplex plate reader (Luminex, Austin, TX).

\section{Statistical analyses}

All results are presented as mean \pm standard deviation for continuous covariates and frequencies and percentages for categorical variables. We used a two-way ANOVA for continuous variables and chi-squared tests for categorical variables to compare GDM and normal patients. A two-tailed significance level of 0.05 was used in all tests. Statistical analyses were performed using SAS software (SAS 9.4 Institute, Inc., Cary, NC). Due to the similarities between the groups at baseline, multivariate analysis was not performed.

\section{Clinical data collection}

Following delivery, we performed a retrospective chart analysis in the electronic medical record to assess for pregnancies complicated by pre-eclampsia, small or large for gestational age babies, $\mathrm{C}$-section delivery, neonatal hypoglycemia, early labor ( $<37$ weeks), and maternal treatment for GDM.

\section{Results}

Forty-six women with normal glucose tolerance (NGT) and 47 women with GDM were included in the study. There were no significant differences between subjects with GDM and those without in terms of maternal age, gestational age, body mass index (BMI), mean arterial pressure, and race/ethnicity (Table 1 ). There were no significant differences in daily medication use or past medical history. One subject in the GDM group had a history of GDM, and one subject in the GDM group had a history of hypothyroidism. No other endocrine abnormalities were reported in any of the other subjects. Treatment of GDM was determined by clinician preference and included diet (23 subjects), glyburide (24 subjects), or glyburide+insulin (one subject).

Serum concentrations of HGF, OPG, TRAIL, prolactin, TNF $\alpha$, and PAI- 1 were not significantly different between those with NGT and those with GDM (Table 2). Serum RANKL was significantly lower in patients with GDM ( $40.15 \pm 28.55$ vs. $27.95 \pm 27.59, p=0.019)$.

As has been previously demonstrated, there was a trend toward increased rates of C-section, macrosomia, and preterm delivery in patients with GDM (Table 3). Two patients in the NGT group and three patients in the gestational diabetes group did not have clinical outcomes data available. However, the results did not meet
Table 1. Patient Characteristics

\begin{tabular}{lcccc}
\hline Patient characteristics & $\begin{array}{c}\text { Over all } \\
(\boldsymbol{n}=\mathbf{9 3})\end{array}$ & $\begin{array}{c}\text { NGT } \\
(\boldsymbol{n}=\mathbf{4 6 )}\end{array}$ & $\begin{array}{c}\text { GDM } \\
(\boldsymbol{n}=\mathbf{4 7})\end{array}$ & $\boldsymbol{p}$ \\
\hline Clinical & & & & \\
$\quad$ Maternal age, years & $31.6 \pm 5.7$ & $31.48 \pm 6.16$ & $31.43 \pm 4.12$ & 0.865 \\
Gestational age, weeks & $28.1 \pm 2.2$ & $28.02 \pm 1.71$ & $28.69 \pm 2.37$ & 0.671 \\
BMI & $30.7 \pm 6.6$ & $30.4 \pm 7.69$ & $29.15 \pm 4.71$ & 0.643 \\
MAP & $81.0 \pm 7.7$ & $80.27 \pm 7.66$ & $81.2 \pm 8.9$ & 0.395 \\
Race/Ethnicity, $n$ (\%) & & & & 0.518 \\
Asian & $17(18.3)$ & $6(13.04)$ & $11(23.4)$ & \\
African American & $13(14.0)$ & $8(17.39)$ & $5(10.64)$ & \\
Caucasian/Non-Hispanic & $13(14.0)$ & $8(17.39)$ & $5(10.64)$ & \\
Hispanic & $45(48.4)$ & $21(45.65)$ & $24(51.06)$ & \\
$\quad$ Unknown & $5(5.4)$ & $3(6.52)$ & $2(4.26)$ & \\
\hline
\end{tabular}

BMI, body mass index; GDM, gestational diabetes mellitus; NGT, normal glucose tolerance.

statistical significance as the study was not powered to detect differences in clinical outcomes. BMI was statistically significantly higher in individuals with pre-eclampsia compared with subjects with NGT $(34.8 \pm 9.7$ vs. 30.4 $\pm 5.6, p=0.021)$. Mean arterial pressure was also higher in individuals with pre-eclampsia compared with those without $(86.7 \pm 7.3$ vs. $79.7 \pm 7.4, p=0.002)$.

\section{Discussion}

In the present study, we found that serum RANKL was significantly lower in women with GDM compared with those with NGT, even when adjusted for age, BMI, and gestational age. However, no significant differences were observed for serum values of HGF, TRAIL, OPG, prolactin, TNF $\alpha$, and PAI-1 when compared with controls.

GDM is a significant health concern that can lead to maternal and fetal complications. Universal screening of all pregnant women is recommended to identify and treat women with GDM in an effort to reduce complications and improve outcomes. Screening occurs at 24-28 weeks gestation in those without risk factors that would necessitate earlier screening. There are currently two

Table 2. Results of Protein Analysis for Women with Normal Glucose Tolerance and Women with Gestational Diabetes Mellitus

\begin{tabular}{lccc}
\hline & NGT & GDM & $p$ \\
\hline OPG, $\mathrm{pg} / \mathrm{mL}$ & $616.46 \pm 279.02$ & $624.11 \pm 315.88$ & 0.717 \\
RANKL, $\mathrm{pg} / \mathrm{mL}$ & $40.15 \pm 28.55$ & $27.95 \pm 27.59$ & 0.019 \\
TRAlL, $\mathrm{pg} / \mathrm{mL}$ & $110.84 \pm 36.62$ & $103.68 \pm 41.4$ & 0.238 \\
Prolactin, $\mathrm{ng} / \mathrm{mL}$ & $259.61 \pm 139.48$ & $332.33 \pm 173.31$ & 0.127 \\
$\mathrm{HGF}, \mathrm{pg} / \mathrm{mL}$ & $118.47 \pm 71.12$ & $124.08 \pm 69.21$ & 0.652 \\
TNF $\alpha, \mathrm{pg} / \mathrm{mL}$ & $2.61 \pm 1.29$ & $2.74 \pm 1.1$ & 0.604 \\
PAl-1 (total), $\mathrm{ng} / \mathrm{mL}$ & $632.01 \pm 281.45$ & $639.44 \pm 312.51$ & 0.904 \\
\hline
\end{tabular}

HGF, hepatocyte growth factor; OPG, osteoprotegerin; PAI-1, plasminogen activator inhibitor type 1; RANKL, receptor activator of nuclear factor-kappa B ligand; TNF $\alpha$, tumor necrosis factor alpha; TRAIL, tumor necrosis factor-related apoptosis-inducing ligand. 
Table 3. Clinical Outcomes

\begin{tabular}{lccc}
\hline & NGT $(\boldsymbol{n}=\mathbf{4 4 )}$ & GDM $(\boldsymbol{n}=\mathbf{4 4})$ & $\boldsymbol{p}$ \\
\hline Macrosomia (>4000 g) & 2 & 5 & 0.435 \\
Preterm delivery & 2 & 6 & 0.266 \\
$\quad$ (before 37 weeks) & 7 & 7 & 1 \\
$\begin{array}{l}\text { Pre-eclampsia } \\
\text { C-section }\end{array}$ & 16 & 20 & 0.386 \\
\hline
\end{tabular}

Clinical outcomes were obtained from 44 women with NGT and 44 women with GDM. Two patients in the NGT group and three patients in the gestational diabetes group did not have clinical outcomes data available.

options to diagnose GDM. In the one-step oral glucose screening approach, put forth by the International Association of Diabetes and Pregnancy Study Group (IADPSG) in $2010,{ }^{18} \mathrm{GDM}$ is diagnosed if, after a $75 \mathrm{~g}$ OGTT, any one of the criteria are met: fasting serum glucose $\geq 92 \mathrm{mg} / \mathrm{dL}, 1 \mathrm{~h} \geq 180 \mathrm{mg} / \mathrm{dL}$, or $2 \mathrm{~h} \geq 152 \mathrm{mg} / \mathrm{dL}$. Alternatively, the two-step strategy may also be employed, in which case patients are first given a $50 \mathrm{~g}$ nonfasting glucose load. If the $1 \mathrm{~h}$ plasma glucose is $>140$, as recommended by the American Diabetes Association, or $135 \mathrm{mg} / \mathrm{dL}$, as recommended by American College of Obstetricians and Gynecologists for high-risk populations, patients then undergo a $100 \mathrm{~g}$ OGTT. ${ }^{19}$ Women are diagnosed with GDM if two of following glucose values are met or exceeded: fasting $>95 \mathrm{mg} / \mathrm{dL}$, $>180 \mathrm{mg} / \mathrm{dL}, 2 \mathrm{~h}>155 \mathrm{mg} / \mathrm{dL}$, or $3 \mathrm{~h}>140 \mathrm{mg} / \mathrm{dL}$.

Untreated gestational diabetes increases the risk of shoulder dystocia, large for gestational age babies, and cesarean delivery. ${ }^{20}$ Many studies indicate that children born to mothers with diabetes mellitus are at increased risk for childhood obesity and diabetes later in life, risks independent of environment and genetics. ${ }^{1}$ Approximately $20-60 \%$ of women with GDM will go on to develop diabetes mellitus within 5-10 years postpartum, with about $10 \%$ being diagnosed shortly after delivery. ${ }^{1}$ Additionally, those with a history of GDM, and even those with impaired glucose tolerance (IGT) during pregnancy, have a higher cardiovascular risk than women who never had GDM. ${ }^{21}$

Given the cumbersome nature of diagnostic tests and the potential catastrophic consequences of GDM, discovering easier methods to diagnose and prognosticate the severity of GDM, including at earlier periods in pregnancy, could help improve outcomes. We set out to determine whether there was an association between GDM and various biochemical and protein markers.

Receptor activator of nuclear factor-kappa B ligand

RANKL is a 317-amino acid peptide that leads to activation of NF- $\kappa$ B when bound to its receptor. ${ }^{22}$ RANKL is secreted by immature osteoblast-lineage cells, osteocytes, and T lymphocytes, and its primary function is the stimulation of osteoclast differentiation and activity, as well as prevention of osteoclast apoptosis. ${ }^{23,24}$ RANKL is regulated by various cytokines and hormones, including TNF, IL-1, IL-4, IL-6, IL-11, IL-17, glucocorticoids, vitamin $\mathrm{D}$, and estrogen. ${ }^{25-27}$ Interestingly, associations with RANKL and activity in other tissues and with diseases other than bone are being investigated, including breast cancer and cardiovascular disease. ${ }^{28,29}$

In normal pregnancies, the serum level of RANKL shows variation. One study demonstrated that RANKL levels were significantly higher in the second trimester of normal pregnancy when compared with the first and third trimesters. ${ }^{30}$ Additionally, RANKL is essential for mammary development in pregnant mice, although it is not essential for the development of breast tissue before pregnancy. ${ }^{31}$ In pregnancies complicated by pre-eclampsia, one study showed soluble RANKL in peripartum and postpartum period were not different from healthy controls, but the OPG/RANKL ratio was higher due to higher levels of OPG in patients with pre-eclampsia. ${ }^{32}$ Another study showed a trend toward lower RANKL levels in patients with preeclampsia in the third trimester, but the difference did not reach statistical significance ${ }^{30}$

In our study, serum RANKL levels were found to be lower in women with GDM. Prior research has been conflicting, with some studies reporting no difference in RANKL in pregnant women with GDM compared with non-GDM. ${ }^{12,33}$ Alternatively, the prospective population-based Bruneck study showed that a high serum concentration of RANKL was a risk factor for the development of T2DM in nonpregnant humans. ${ }^{34}$ Animal models in nonpregnant mice with knock out of hepatocyte RANKL had improved hepatic insulin sensitivity and improved glucose tolerance when compared with wild-type mice. ${ }^{34}$ Additionally, activation of NF- $\kappa \mathrm{B}$ (such as occurred by RANKL), has been shown to be a mediator implicated in hepatic insulin resistance and $\beta$ cell loss, which would suggest that RANKL levels should have been higher in our GDM patients. ${ }^{35,36}$ In human and mouse islet cells, Kondegowda et al. showed that RANKL stops $\beta$ cell proliferation, which can be overcome by administration of OPG. Furthermore, treatment of islets with denosumab, a monoclonal antibody against RANKL, increased $\beta$ cell proliferation of human islets transplanted into rodents. ${ }^{37}$

It is unclear why our data in pregnant women differ from other reports in the literature of RANKL in 
pregnant and nonpregnant subjects. The state of pregnancy may cause changes in multiple factors which affect RANKL and other proteins, and this could explain the disagreement between our results and those in the literature looking at nonpregnant subjects.

It is possible that lower levels of RANKL in the serum of women with GDM were a consequence of elevated blood glucose. In patients with hyperglycemia, advanced glycation end products (AGEs) deteriorate bone quality. An in vitro study evaluating mouse osteocytes showed that AGEs decreased RANKL expression. ${ }^{38}$ However, an in vitro study looking at human osteoblasts found increased RANKL mRNA expression in the setting of AGEs. ${ }^{39}$ Additionally, other studies have shown that osteoblasts exposed to high glucose environment demonstrated no effect ${ }^{40}$ or increased RANKL expression, so further study is needed. ${ }^{41,42}$

It is also possible that serum levels of RANKL are not indicative of activity at the tissue level. Serum levels of RANKL have been found to be variable even in patients with metabolic bone disease, and currently RANKL is not used clinically as a marker of fracture risk or osteoporosis due to this variability. Studies are conflicting, showing both no difference and elevated levels in patients at high risk for fracture. ${ }^{43,44}$ Finally, assays used to measure RANKL in serum are imperfect. Most assays measure free RANKL, which has an unclear relationship with the amount of RANKL in the circulation bound to OPG and other serum-binding proteins. ${ }^{45}$

Hepatocyte growth factor

Initially discovered in the 1980s as a protein responsible in liver regeneration, HGF is a growth factor produced by liver and placental tissues that promotes cell survival and tissue regeneration with targets found in many organs, including the liver, the pancreas, the kidneys, the heart, and the placenta. ${ }^{46}$ Pregnant knockout (KO) mice of the HGF receptor, c-Met, in the pancreas (PancMet KO mice), had a significant decrease in $\beta$ cell mass due to decreased $\beta$ cell replication as well as a premature apoptosis of $\beta$ cells at gestational day 19 , which correlated with the time of maximal $\beta$ cell expansion in healthy pregnant mice. ${ }^{11}$ Blood glucose values were significantly higher in pregnant PancMet $\mathrm{KO}$ mice and were associated with lower plasma insulin levels. Additionally, IGT was noted before a change in $\beta$ cell mass. These data suggest that $\mathrm{HGF} / \mathrm{c}-$ Met has an important role in normal maternal $\beta$ cell expansion and survival during pregnancy. In addition, HGF may increase insulin secretion in ways independent of the effect on $\beta$ cell mass. ${ }^{11}$ HGF con- centrations in maternal serum are below detection level before 10 weeks gestation but increase steadily after until the end of the third trimester. ${ }^{47,48}$ Maternal plasma HGF levels are decreased in women with small for gestational age infants ${ }^{49,50}$ and in severe pre-eclampsia. ${ }^{51}$ In nonpregnant adults, HGF is found to correlate with hyperinsulinemia in insulin resistance in obese patients with metabolic syndrome. ${ }^{52}$ Our study did not find a difference in serum values of HGF between patients with GDM and those with NGT. Factors contributing to the difference between our results and the literature could be that murine and human physiology are dissimilar with regard to HGF, that BMI in both our subject groups is not different, or that polymorphisms in HGF or its receptor may explain the difference, but further study is warranted.

\section{Prolactin}

Prolactin's role in sustaining $\beta$ cell mass and glucose homeostasis has been elucidated by in vitro and in vivo rodent studies. In rats, expression of the prolactin receptor on maternal islets increases during pregnancy, and treatment of islets with prolactin in culture leads to increases in insulin secretion. ${ }^{53,54}$ Studies in $\mathrm{KO}$ mice indicate that prolactin and placental lactogen are required to maintain appropriate $\beta$ cell mass and glucose homeostasis during pregnancy. ${ }^{55}$ In humans, a study comparing plasma prolactin levels in GDM versus non-GDM individuals showed no difference between the groups during pregnancy. ${ }^{56}$ Similarly, we did not find a statistically significant difference in prolactin levels between GDM and non-GDM subjects. Therefore, if impaired placental lactogen signaling on $\beta$ cells contributes to the GDM phenotype, it is likely due to deficits at the receptor level rather than a decline in circulating prolactin.

\section{Osteoprotegerin}

Consistent with prior reports, we did not find a difference in serum OPG levels for subjects with and without GDM. ${ }^{12}$ OPG is a soluble decoy receptor that is a member of the TNF receptor superfamily. OPG binds to RANKL, thereby inhibiting osteoclastic bone resorption. Plasma levels of OPG have not been associated with bone mineral density or fractures, but have been associated with cardiovascular mortality. ${ }^{57}$ Previous studies have shown that OPG increases during pregnancy, followed by a rapid postpartum decline. ${ }^{58}$ Akinci et al. showed that women with previous GDM developing metabolic syndrome had higher OPG levels than those without metabolic syndrome and healthy controls. ${ }^{59}$ 
The Dallas Heart Study found that non-GDM was associated with higher plasma OPG levels, which was also associated with cardiovascular mortality. ${ }^{60}$ In our study, circulating OPG levels did not differ between the groups.

Tumor necrosis factor-related

apoptosis-inducing ligand

TRAIL induces apoptosis through interactions with death receptors. ${ }^{61}$ TRAIL and TRAIL receptors are expressed on the placenta and are involved in immune privilege of trophoblasts as well as trophoblastic invasion. Placental microparticles regularly are released into the circulation and therefore plasma measurements of placental proteins, such as TRAIL may be measurable in the serum. ${ }^{62}$ Women with hypertensive diseases in pregnancy were found to have significantly lower plasma TRAIL levels compared with women with uncomplicated pregnancies. ${ }^{13}$ Additionally, blocking TRAIL function in murine models of type 1 diabetes leads to increased autoimmune inflammation in the pancreatic islets. ${ }^{63} \mathrm{We}$ did not find a difference in plasma TRAIL level between individuals with GDM and those without. However, investigation of TRAIL function in placental or $\beta$ cell tissue may elucidate different findings.

\section{Tumor necrosis factor alpha}

$\mathrm{TNF} \alpha$ has been implicated in insulin resistance in pregnant and nonpregnant rodents and humans. ${ }^{64-67}$ Pregnant women without diabetes have been found to have increased levels of TNF $\alpha$ as pregnancy progresses. ${ }^{68}$ Multiple studies, including a meta-analysis have shown significantly higher levels of serum $\mathrm{TNF} \alpha$ in patients with GDM. ${ }^{15-17}$ Correlation with circulating TNF $\alpha$ and insulin resistance in pregnancy has been confirmed elsewhere, and TNF $\alpha$ also correlates with BMI. ${ }^{68,69}$ Our findings did not support differences in TNF $\alpha$ levels in individuals with GDM, similar to another report by Georgiou et al. ${ }^{70}$ It is possible that we were not powered to detect differences in $\mathrm{TNF} \alpha$, or that high BMI levels and partial insulin resistance in the controls made it more difficult to detect differences.

\section{Plasminogen activator inhibitor type 1}

PAI-1 has multiple functions, including tumorigenesis, angiogenesis, wound healing, ovulation, and regulation of anti-fibrinolytic activity of the plasma. ${ }^{71,72}$ Elevated plasma levels of PAI-1 have been found to be associated with insulin resistance, type 2 diabetes, and obesity. ${ }^{73,74}$ In 2004, Winzer et al. showed that women with previous GDM had higher serum levels of PAI-1 when compared with women with NGT during a previous pregnancy. ${ }^{75}$ Leipold et al. found that genetic polymorphisms of the PAI-1 gene increased the risk of gestational diabetes. ${ }^{76}$ In our study, women with GDM had similar plasma levels of PAI-1 when compared with controls. However, since we do not have data on genetic analysis, it is possible that genetic polymorphisms existed in some of our women with GDM.

\section{Limitations}

There were some limitations to this study. Plasma drawn for analysis were obtained during 1-h GCT or 3-h GTT. The timing of the sample collection from time of glucose load was not controlled. It is possible that the glucose load before specimen collection or ambient glucose levels at the time of collection could have had an effect on plasma levels of the proteins that were analyzed. Additionally, there were a number of women who tested negative for GDM during their 3-h GTT, but had failed their 1-h GCT. Therefore, they were considered controls in our study, but possibly had some mild insulin resistance and glucose intolerance which may have affected the results. All blood draws occurred during weeks $24-32$, so it is unknown if a difference would have been noted if drawn later or earlier in pregnancy. Additionally, white women were under-represented in our study, as most of our subjects were African American or Hispanic. Many of the other reports published in the literature have a higher representation of Caucasian subjects, making it possible that race or ethnicity impacts the cytokine/ protein profile of women during pregnancy, explaining our failure to confirm the findings of other researchers. Finally, due to the cross-sectional design of the study, it is not possible to derive a causal link between RANKL levels and GDM.

\section{Conclusions and Future Directions}

GDM can have complications to the mother and the fetus. While the exact mechanism of GDM has not been elucidated, recent studies have suggested that various serum proteins may contribute to or correlate with GDM. In our study, serum HGF, OPG, prolactin, TRAIL, TAI-1, and TNF $\alpha$ were similar in women with and without GDM, but RANKL levels were lower in women with GDM. Further investigation is needed to determine whether there are suitable serum markers for diagnosing GDM or determining prognosis or severity. Future work, including larger sample sizes and tissue analysis, could help elucidate whether serum RANKL levels or other proteins could be useful in this regard. 


\section{Acknowledgments}

The authors would like to acknowledge Emilia Bagiella, $\mathrm{PhD}$ for her assistance with statistical work; Elina Trofimovsky, MD, Khadeen C. Cheesman, MD, and Mirella Mourad, MD for their assistance with patient recruitment; and laboratory technician, Jayalakshmi Lakshmipathi, $\mathrm{PhD}$ for assistance with protein analysis.

\section{Author Disclosure Statement}

\section{No competing financial interests exist.}

\section{References}

1. Buchanan TA, Xiang AH, Page KA. Gestational diabetes mellitus: risks and management during and after pregnancy. Nat Rev Endocrinol. 2012;8: 639-649.

2. Xiang $\mathrm{AH}$, $\mathrm{Li} \mathrm{BH}$, Black $\mathrm{MH}$, et al. Racial and ethnic disparities in diabetes risk after gestational diabetes mellitus. Diabetologia. 2011;54:3016-3021.

3. Kuhl C. Insulin secretion and insulin resistance in pregnancy and GDM. Implications for diagnosis and management. Diabetes. 1991;40(Suppl 2):18-24.

4. Bone AJ, Taylor KW. Mitabolic adaptation to pregnancy shown by increased biosynthesis of insulin in islets of Langerhans isolated from pregnant rat. Nature. 1976;262:501-502.

5. Green IC, Howell SL, Montague W, et al. Regulation of insulin release from isolated islets of Langerhans of the rat in pregnancy. The role of adenosine 3':5'-cyclic monophosphate. Biochem J. 1973;134:481-487.

6. Green IC, Taylor KW. Effects of pregnancy in the rat on the size and insulin secretory response of the islets of Langerhans. J Endocrinol. 1972;54:317-325.

7. Van Assche FA, Aerts L, Gepts W. Morphological changes in the endocrine pancreas in pregnant rats with experimental diabetes. J Endocrinol. 1979; 80:175-179.

8. Parsons JA, Brelje TC, Sorenson RL. Adaptation of islets of Langerhans to pregnancy: increased islet cell proliferation and insulin secretion correlates with the onset of placental lactogen secretion. Endocrinology. 1992; 130:1459-1466.

9. Sorenson RL, Brelje TC. Adaptation of islets of Langerhans to pregnancy: beta-cell growth, enhanced insulin secretion and the role of lactogenic hormones. Horm Metab Res. 1997;29:301-307.

10. Barbour LA, McCurdy CE, Hernandez TL, et al. Cellular mechanisms for insulin resistance in normal pregnancy and gestational diabetes. Diabetes Care. 2007;30(Suppl 2):S112-S119.

11. Demirci C, Ernst S, Alvarez-Perez JC, et al. Loss of HGF/c-Met signaling in pancreatic beta-cells leads to incomplete maternal beta-cell adaptation and gestational diabetes mellitus. Diabetes. 2012;61:1143-1152.

12. Telejko B, Kalejta K, Kuzmicki M, et al. The association of bone turnover markers with pro- and anti-inflammatory adipokines in patients with gestational diabetes. Ann Agric Environ Med. 2015;22:307-312.

13. Zhou C, Long Y, Yang H, et al. TRAIL is decreased before 20 weeks gestation in women with hypertensive disorders of pregnancy. PLoS One. 2015;10:e0128425.

14. Mellado-Gil J, Rosa TC, Demirci C, et al. Disruption of hepatocyte growth factor/c-Met signaling enhances pancreatic beta-cell death and accelerates the onset of diabetes. Diabetes. 2011;60:525-536.

15. Xu J, Zhao YH, Chen YP, et al. Maternal circulating concentrations of tumor necrosis factor-alpha, leptin, and adiponectin in gestational diabetes mellitus: a systematic review and meta-analysis. ScientificWorldJournal. 2014;2014:926932.

16. Lopez-Tinoco C, Roca M, Fernandez-Deudero A, et al. Cytokine profile, metabolic syndrome and cardiovascular disease risk in women with lateonset gestational diabetes mellitus. Cytokine. 2012;58:14-19.

17. Gao XL, Yang HX, Zhao Y. Variations of tumor necrosis factor-alpha, leptin and adiponectin in mid-trimester of gestational diabetes mellitus. Chin Med J (Engl). 2008;121:701-705.

18. International Association of Diabetes and Pregnancy Study Groups Consensus, Metzger BE, Gabbe SG, et al. International association of diabetes and pregnancy study groups recommendations on the diagnosis and classification of hyperglycemia in pregnancy. Diabetes Care. 2010;33:676-682.
19. Chamberlain JJ, Rhinehart AS, Shaefer CF, Jr., et al. Diagnosis and management of diabetes: synopsis of the 2016 American Diabetes Association Standards of Medical Care in Diabetes. Ann Intern Med. 2016;164:542-552.

20. Langer O, Yogev $Y$, Most O, et al. Gestational diabetes: the consequences of not treating. Am J Obstet Gynecol. 2005;192:989-997.

21. Sullivan SD, Umans JG, Ratner R. Gestational diabetes: implications for cardiovascular health. Curr Diab Rep. 2012;12:43-52.

22. Anderson DM, Maraskovsky $E$, Billingsley $\mathrm{WL}$, et al. $A$ homologue of the TNF receptor and its ligand enhance T-cell growth and dendritic-cell function. Nature. 1997;390:175-179.

23. Lacey DL, Timms E, Tan HL, et al. Osteoprotegerin ligand is a cytokine that regulates osteoclast differentiation and activation. Cell. 1998;93:165-176.

24. Malyankar UM, Scatena M, Suchland KL, et al. Osteoprotegerin is an alpha vbeta 3-induced, NF-kappa B-dependent survival factor for endothelial cells. J Biol Chem. 2000;275:20959-20962.

25. Hofbauer LC, Khosla S, Dunstan CR, et al. Estrogen stimulates gene expression and protein production of osteoprotegerin in human osteoblastic cells. Endocrinology. 1999;140:4367-4370.

26. Hofbauer LC, Lacey DL, Dunstan CR, et al. Interleukin-1 beta and tumor necrosis factor-alpha, but not interleukin-6, stimulate osteoprotegerin ligand gene expression in human osteoblastic cells. Bone. 1999;25:255-259.

27. Kitazawa S, Kajimoto K, Kondo T, et al. Vitamin D3 supports osteoclastogenesis via functional vitamin $D$ response element of human RANKL gene promoter. J Cell Biochem. 2003;89:771-777.

28. Giaginis C, Papadopouli A, Zira A, et al. Correlation of plasma osteoprotegerin (OPG) and receptor activator of the nuclear factor kappaB ligand (RANKL) levels with clinical risk factors in patients with advanced carotid atherosclerosis. Med Sci Monit. 2012;18:CR597-CR604.

29. Thomas RJ, Guise TA, Yin JJ, et al. Breast cancer cells interact with osteoblasts to support osteoclast formation. Endocrinology. 1999;140:4451-4458.

30. Dorota DK, Bogdan KG, Mieczyslaw G, et al. The concentrations of markers of bone turnover in normal pregnancy and preeclampsia. Hypertens Pregnancy. 2012;31:166-176.

31. Fata JE, Kong YY, Li J, et al. The osteoclast differentiation factor osteoprotegerin-ligand is essential for mammary gland development. Cell. 2000;103:41-50.

32. Vitoratos N, Lambrinoudaki I, Rizos D, et al. Maternal circulating osteoprotegerin and soluble RANKL in pre-eclamptic women. Eur J Obstet Gynecol Reprod Biol. 2011;154:141-145.

33. Gumus P, Ozcaka O, Ceyhan-Ozturk B, et al. Evaluation of biochemical parameters and local and systemic levels of osteoactive and B-cell stimulatory factors in gestational diabetes in the presence or absence of gingivitis. J Periodontol. 2015;86:387-397.

34. Kiechl S, Wittmann J, Giaccari A, et al. Blockade of receptor activator of nuclear factor-kappaB (RANKL) signaling improves hepatic insulin resistance and prevents development of diabetes mellitus. Nat Med. 2013;19:358-363.

35. Cai D, Yuan M, Frantz DF, et al. Local and systemic insulin resistance resulting from hepatic activation of IKK-beta and NF-kappaB. Nat Med. 2005; 11:183-190.

36. Eldor R, Yeffet A, Baum K, et al. Conditional and specific NF-kappaB blockade protects pancreatic beta cells from diabetogenic agents. Proc Natl Acad Sci U S A. 2006;103:5072-5077.

37. Kondegowda NG, Fenutria R, Pollack IR, et al. Osteoprotegerin and denosumab stimulate human beta cell proliferation through inhibition of the receptor activator of NF-kappaB ligand pathway. Cell Metab. 2015;22:77-85.

38. Tanaka K, Yamaguchi T, Kanazawa I, et al. Effects of high glucose and advanced glycation end products on the expressions of sclerostin and RANKL as well as apoptosis in osteocyte-like MLO-Y4-A2 cells. Biochem Biophys Res Commun. 2015;461:193-199.

39. Franke S, Siggelkow H, Wolf $G$, et al. Advanced glycation endproducts influence the mRNA expression of RAGE, RANKL and various osteoblastic genes in human osteoblasts. Arch Physiol Biochem. 2007;113:154-161.

40. Shao X, Cao X, Song G, et al. Metformin rescues the MG63 osteoblasts against the effect of high glucose on proliferation. J Diabetes Res. 2014; 2014:453940.

41. Garcia-Hernandez A, Arzate H, Gil-Chavarria I, et al. High glucose concentrations alter the biomineralization process in human osteoblastic cells. Bone. 2012;50:276-288.

42. Cunha JS, Ferreira VM, Maquigussa E, et al. Effects of high glucose and high insulin concentrations on osteoblast function in vitro. Cell Tissue Res. 2014;358:249-256. 
43. LaCroix AZ, Jackson RD, Aragaki $A$, et al. OPG and sRANKL serum levels and incident hip fracture in postmenopausal Caucasian women in the Women's Health Initiative Observational Study. Bone. 2013;56:474-481.

44. Schett G, Kiechl S, Redlich K, et al. Soluble RANKL and risk of nontraumatic fracture. JAMA. 2004;291:1108-1113.

45. Findlay DM, Atkins GJ. Relationship between serum RANKL and RANKL in bone. Osteoporos Int. 2011;22:2597-2602.

46. Nakamura T, Sakai K, Nakamura T, et al. Hepatocyte growth factor twenty years on: much more than a growth factor. J Gastroenterol Hepatol. 2011; 26(Suppl 1):188-202.

47. Horibe N, Okamoto T, Itakura A, et al. Levels of hepatocyte growth factor in maternal serum and amniotic fluid. Am J Obstet Gynecol. 1995;173(3 Pt 1):937-942.

48. Vuorela P, Sarkola T, Alfthan H, et al. Hepatocyte growth factor, epidermal growth factor, and placenta growth factor concentrations in peripheral blood of pregnant women with alcohol abuse. Alcohol Clin Exp Res. 2002; 26:682-687.

49. Aoki S, Hata T, Manabe A, et al. Decreased maternal circulating hepatocyte growth factor (HGF) concentrations in pregnancies with small for gestational age infants. Hum Reprod. 1998;13:2950-2953.

50. Tjoa ML, Mulders MA, van Vugt JM, et al. Plasma hepatocyte growth factor as a marker for small-for-gestational age fetuses. Eur J Obstet Gynecol Reprod Biol. 2003;110:20-25.

51. Zeng $X$, Sun $Y$, Yang HX, et al. Plasma level of soluble c-Met is tightly associated with the clinical risk of preeclampsia. Am J Obstet Gynecol. 2009;201:618.e1-618.e7.

52. Hiratsuka A, Adachi H, Fujiura $Y$, et al. Strong association between serum hepatocyte growth factor and metabolic syndrome. J Clin Endocrinol Metab. 2005;90:2927-2931.

53. Moldrup A, Petersen ED, Nielsen JH. Effects of sex and pregnancy hormones on growth hormone and prolactin receptor gene expression in insulin-producing cells. Endocrinology. 1993;133:1165-1172.

54. Sorenson RL, Brelje TC, Roth C. Effects of steroid and lactogenic hormones on islets of Langerhans: a new hypothesis for the role of pregnancy steroids in the adaptation of islets to pregnancy. Endocrinology. 1993;133:2227-2234.

55. Huang C, Snider F, Cross JC. Prolactin receptor is required for normal glucose homeostasis and modulation of beta-cell mass during pregnancy. Endocrinology. 2009;150:1618-1626.

56. Skouby SO, Kuhl C, Hornnes PJ, et al. Prolactin and glucose tolerance in normal and gestational diabetic pregnancy. Obstet Gynecol. 1986;67: 17-20.

57. Browner WS, Lui LY, Cummings SR. Associations of serum osteoprotegerin levels with diabetes, stroke, bone density, fractures, and mortality in elderly women. J Clin Endocrinol Metab. 2001;86:631-637.

58. Naylor KE, Rogers A, Fraser RB, et al. Serum osteoprotegerin as a determinant of bone metabolism in a longitudinal study of human pregnancy and lactation. J Clin Endocrinol Metab. 2003;88:5361-5365.

59. Akinci B, Celtik A, Yuksel F, et al. Increased osteoprotegerin levels in women with previous gestational diabetes developing metabolic syndrome. Diabetes Res Clin Pract. 2011;91:26-31.

60. Abedin M, Omland T, Ueland T, et al. Relation of osteoprotegerin to coronary calcium and aortic plaque (from the Dallas Heart Study). Am J Cardiol. 2007;99:513-518.

61. Pitti RM, Marsters SA, Ruppert S, et al. Induction of apoptosis by Apo-2 ligand, a new member of the tumor necrosis factor cytokine family. J Biol Chem. 1996;271:12687-12690.

62. Redman CW, Sargent IL. Circulating microparticles in normal pregnancy and pre-eclampsia. Placenta. 2008;29(Suppl A):S73-S77.

63. Lamhamedi-Cherradi SE, Zheng S, Tisch RM, et al. Critical roles of tumor necrosis factor-related apoptosis-inducing ligand in type 1 diabetes. Diabetes. 2003;52:2274-2278.

64. Winkler G, Lakatos P, Salamon F, et al. Elevated serum TNF-alpha level as a link between endothelial dysfunction and insulin resistance in normotensive obese patients. Diabet Med. 1999;16:207-211.

65. Saghizadeh M, Ong JM, Garvey WT, et al. The expression of TNF alpha by human muscle. Relationship to insulin resistance. J Clin Invest. 1996;97: 1111-1116.

66. Liu LS, Spelleken M, Rohrig K, et al. Tumor necrosis factor-alpha acutely inhibits insulin signaling in human adipocytes: implication of the p80 tumor necrosis factor receptor. Diabetes. 1998:47:515-522.

67. Cawthorn WP, Sethi JK. TNF-alpha and adipocyte biology. FEBS Lett. 2008; 582:117-131.
68. Winkler G, Cseh K, Baranyi E, et al. Tumor necrosis factor system in insulin resistance in gestational diabetes. Diabetes Res Clin Pract. 2002;56:93-99.

69. Kirwan JP, Hauguel-De Mouzon S, Lepercq J, et al. TNF-alpha is a predictor of insulin resistance in human pregnancy. Diabetes. 2002;51:2207-2213.

70. Georgiou HM, Lappas M, Georgiou GM, et al. Screening for biomarkers predictive of gestational diabetes mellitus. Acta Diabetol. 2008:45:157-165.

71. Correia ML, Haynes WG. A role for plasminogen activator inhibitor-1 in obesity: from pie to PAI? Arterioscler Thromb Vasc Biol. 2006;26:2183-2185.

72. Feinbloom D, Bauer KA. Assessment of hemostatic risk factors in predicting arterial thrombotic events. Arterioscler Thromb Vasc Biol. 2005;25: 2043-2053.

73. Alessi MC, Bastelica D, Morange $P$, et al. Plasminogen activator inhibitor 1, transforming growth factor-beta1, and BMI are closely associated in human adipose tissue during morbid obesity. Diabetes. 2000;49:1374-1380.

74. Festa A, D'Agostino R, Jr., Tracy RP, et al. Elevated levels of acute-phase proteins and plasminogen activator inhibitor-1 predict the development of type 2 diabetes: the insulin resistance atherosclerosis study. Diabetes. 2002;51:1131-1137.

75. Winzer C, Wagner O, Festa A, et al. Plasma adiponectin, insulin sensitivity, and subclinical inflammation in women with prior gestational diabetes mellitus. Diabetes Care. 2004;27:1721-1727.

76. Leipold $\mathrm{H}$, Knoefler $\mathrm{M}$, Gruber $\mathrm{C}$, et al. Plasminogen activator inhibitor gene polymorphism and gestational diabetes mellitus. Obstet Gynecol. 2006;107:651-656.

Cite this article as: Eschler DC, Kulina G, Garcia-Ocana A, Li J, Kraus T, Levy CJ (2018) Circulating levels of bone and inflammatory markers in gestational diabetes mellitus, BioResearch Open Access 7:1, 123-130, DOI: $10.1089 /$ biores.2018.0013.

Abbreviations Used
$\mathrm{AGES}=$ advanced glycation end products
$\mathrm{BMI}=$ body mass index
$\mathrm{GDM}=$ gestational diabetes mellitus
$\mathrm{HGF}=$ hepatocyte growth factor
$\mathrm{IGT}=$ impaired glucose tolerance
$\mathrm{KO}=$ knockout
$\mathrm{NGT}=$ normal glucose tolerance
$\mathrm{OGCT}=$ oral glucose challenge test
$\mathrm{OGTT}=$ oral glucose tolerance test
$\mathrm{OPG}=$ osteoprotegerin
$\mathrm{PAI}-1=$ plasminogen activator inhibitor type 1
$\mathrm{RANKL}=$ receptor activator of nuclear factor-kappa B
$\quad$ ligand
$\mathrm{TNF} \alpha=$ tumor necrosis factor alpha
$\mathrm{TRAIL}=$ tumor necrosis factor-related apoptosis-inducing
$\quad$ ligand

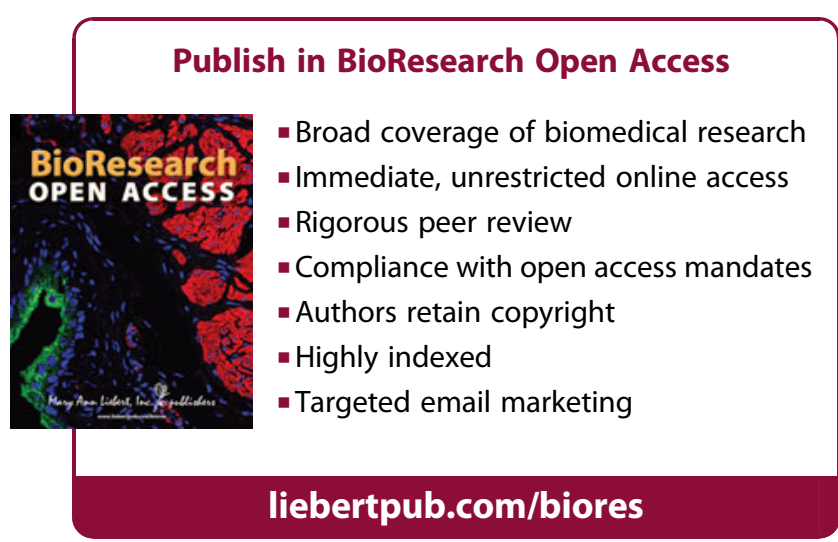

